\title{
Thromboembolic Risks That Require Consideration for Antithrombotic Therapy in Japanese Patients With Atrial Fibrillation
}

\author{
Hiroshi Tada, MD, PhD
}

$\mathbf{T}$ hromboembolic events, consisting of stroke and systemic embolism, are a serious complication of atrial fibrillation (AF), causing a significant morbidity and mortality. Therefore, anticoagulation is an integral part of the therapy for all patients with AF. However, some controversy exists regarding the risk stratification for antithrombotic therapy in non-valvular AF (NVAF). One unsolved issue is wheth- er or not paroxysmal $\mathrm{AF}$ is considered to have the same risk of thromboembolic events as persistent or permanent AF. The thromboembolic risk in patients with paroxysmal AF is comparable to that in permanent AF patients, in some, but not all studies. ${ }^{1-3}$ Whether or not the type of AF affects the prevalence of major bleeding in patients receiving oral anticoagulants is another controversial issue. ${ }^{2,3}$

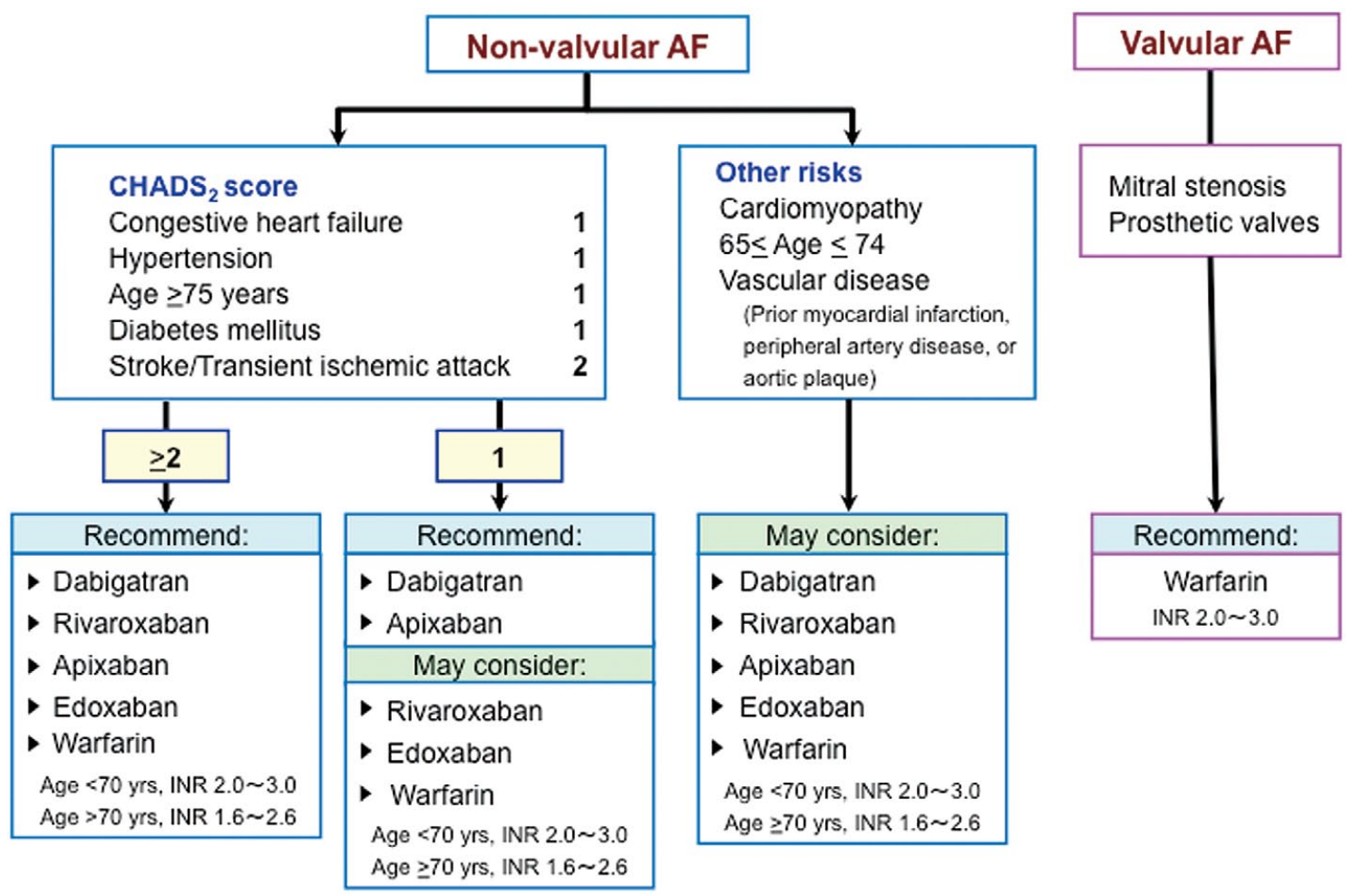

Figure. Antithrombotic therapy in Japanese patients with atrial fibrillation (AF). When both new oral anticoagulants (NOACs) and warfarin can be used, the use of NOACs is desirable. Prosthetic valves include mechanical and bioprosthetic valves. INR, international normalized ratio. Modified with permission from JCS Joint Working Group. ${ }^{12}$

The opinions expressed in this article are not necessarily those of the editors or of the Japanese Circulation Society.

Received August 12, 2014; accepted August 13, 2014; released online August 28, 2014

Department of Cardiovascular Medicine, Faculty of Medical Sciences, University of Fukui, Fukui, Japan

Mailing address: Hiroshi Tada, MD, PhD, Department of Cardiovascular Medicine, Faculty of Medical Sciences, University of Fukui, 23-3

Matsuokashimoaizuki, Eiheiji-cho, Yoshida-gun, Fukui 910-1193, Japan. E-mail: htada@u-fukui.ac.jp

ISSN-1346-9843 doi:10.1253/circj.CJ-14-0914

All rights are reserved to the Japanese Circulation Society. For permissions, please e-mail: cj@j-circ.or.jp 


\begin{tabular}{|lc|}
\hline $\begin{array}{l}\text { Table. } \\
\text { Thromboembolic Risks That Should Be Considered } \\
\text { for Antithrombotic Therapy in Japanese Patients } \\
\text { With Atrial Fibrillation }\end{array}$ \\
C & Congestive heart failure \\
H & Hypertension \\
A & Age $\geq 65$ years \\
D & Diabetes mellitus \\
S & Stroke/transient ischemic attack \\
Vas & Vascular disease \\
C & Cardiomyopathy \\
\hline Vasculation
\end{tabular}

Vascular diseases include a prior myocardial infarction, aortic plaque, and peripheral arterial disease. The mnemonic is "CHADSVasC".

\section{Article p 2388}

It is well known that NVAF differs considerably between Asian and Western countries in terms of the epidemiology, clinical profile, optimal anticoagulation levels etc. ${ }^{4-11}$ Compared with the 5-fold higher likelihood of a stroke among Caucasian patients with AF than in those with sinus rhythm, ${ }^{8}$ the stroke risk related to $\mathrm{AF}$ in Asians is typically lower (a relative risk of 3.70 in Japanese men) ${ }^{4}$ In contrast, the relative risk of AFrelated mortality is comparable between Asian patients (1.88 in Japan) and Caucasians. ${ }^{6}$ The risk of thromboembolic events in anticoagulated AF patients seems to be higher for Asians than Caucasians. ${ }^{5}$ Asian patients have a higher risk of bleeding on warfarin than non-Asians, despite a lower international normalized ratio (INR). ${ }^{6}$ The $\mathrm{CHADS}_{2}$ (congestive heart failure, hypertension, age $\geq 75$ years, diabetes mellitus, and prior stroke/ transient ischemic attack [doubled]) and $\mathrm{CHA}_{2} \mathrm{DS}_{2}-\mathrm{VASc}$ (CHADS 2 components plus vascular disease, age 65-74 years, and sex category [female]) scores, with a widely distributed schema for the risk stratification in NVAF (prosthetic valves and mitral stenosis excluded), are based on studies predominantly in Caucasian populations. ${ }^{8}$ Because of small sample sizes and lack of a detailed follow-up assessment, the efficacy of those scores has not been sufficiently validated in Japanese patients with NVAF.

In this issue of the Journal, with an analysis of the Japanese patients in the prospective observational J-RHYTHM Registry, Inoue et $\mathrm{al}^{9}$ provide some answers to the unsolved issues just described. With a 2-year follow-up of 7,406 NVAF patients, they found that, after adjusting for the $\mathrm{CHA}_{2} \mathrm{DS}_{2}-\mathrm{VASc}$ (or $\mathrm{CHADS}_{2}$ ) components and warfarin use, the risk of thromboembolic events in NVAF patients who were mostly treated with warfarin was comparable between paroxysmal and permanent AF. They also found that the type of AF (paroxysmal, persistent, or permanent) did not significantly affect the prevalence of major hemorrhagic events in patients receiving oral anticoagulation. Recently, with an analysis of the J-RHYTHM Registry, the usefulness of the modified $\mathrm{CHA}_{2} \mathrm{DS}_{2}-\mathrm{VASc}$ score for identifying truly low-risk patients for stroke and systemic thromboembolism and of the modified HAS-BLED (hypertension, abnormal renal/liver function, stroke, bleeding history or predisposition, labile INR, elderly [eg, age $>65$, frailty, etc], and drugs/alcohol concomitantly) score for identifying high-risk patients for major bleeding, especially those treated with warfarin, was reported. ${ }^{10}$ From the significant findings obtained from those studies, ${ }^{9,10}$ it is not too much to say that anticoagulation should be given to Japanese patients with NVAF according to their level of risk for thromboembolism $\left(\mathrm{CHA}_{2} \mathrm{DS}_{2}\right.$-VASc score) and major bleeding (HAS-BLED score), and not according to the type of AF, as in Caucasian patients. ${ }^{8}$

It has become clear that female sex is not a risk factor for thromboembolic events among Japanese patients with NVAF. ${ }^{10,11}$ Cardiomyopathy is a well-known risk for thromboembolic events among Japanese patients with NVAF. ${ }^{12}$ Recent evidence suggests that the new oral anticoagulants (NOACs), direct thrombin inhibitors (dabigatran) and factor Xa inhibitors (rivaroxaban, apixaban, edoxaban) have a favorable risk-benefit profile, with a significant reduction in strokes, intracranial hemorrhage, and mortality, and with a similar or lesser incident of major bleeding than warfarin, ${ }^{13}$ and that NOACs may be particularly more useful for Japanese patients than Caucasian patients. ${ }^{6,7}$

Based on the available data of the risk for thromboembolic events and bleeding during anticoagulation and of the efficacy and safety of anticoagulants, the guidelines for antithrombotic therapy in Japanese patients with AF were announced. ${ }^{12}$ The algorithm for antithrombotic therapy uses all of the risks of thromboembolic events whose significance and utility are demonstrated in Japanese patients (Figure). At this point in time, this guideline is optimal, and should be used for the assessment of the antithrombotic therapy in Japanese patients with NVAF. However, it is becoming clear that thromboembolic events significantly increase with increasing age above 65 years, and not above 75 years. ${ }^{14,15}$ Evidence of the superiority of NOACs over warfarin regarding the efficacy and safety has been accumulating. Therefore, to determine the antithrombotic therapy for AF, a scoring system of the risk factors might become unnecessary. Antithrombotic therapy with NOACs should be considered whenever NVAF patients have any risk of thromboembolic events. If there are any contraindications to NOACs, warfarin is considered as an alternative. In Japanese patients with NVAF, antithrombotic therapy should be considered if there is the presence of congestive heart failure, hypertension, age $\geq 65$ years, diabetes mellitus, stroke/transient ischemic attack, vascular disease, or cardiomyopathy (Table).

\section{Disclosures}

The author does not have a real or perceived conflict of interest.

\section{References}

1. Hart RG, Pearce LA, Rothbart RM, McAnulty JH, Asinger RW, Halperin JL. Stroke with intermittent atrial fibrillation: Incidence and predictors during aspirin therapy: Stroke prevention in atrial fibrillation investigators. J Am Coll Cardiol 2000; 35: 183-187.

2. Al-Khatib SM, Thomas L, Wallentin L, Lopes RD, Gersh B, Garcia $\mathrm{D}$, et al. Outcomes of apixaban vs. warfarin by type and duration of atrial fibrillation: Results from the ARISTOTLE trial. Eur Heart $J$ 2013; 34: 2464-2471.

3. Nieuwlaat R, Dinh T, Olsson SB, Camm AJ, Capucci A, Tieleman $\mathrm{RG}$, et al. Should we abandon the common practice of withholding oral anticoagulation in paroxysmal atrial fibrillation? Eur Heart $J$ 2008; 29: 915-922.

4. Tse HF, Wang YJ, Ahmed Ai-Abdullah M, Pizarro-Borromeo AB, Chiang CE, Krittayaphong R, et al. Stroke prevention in atrial fibrillation: An Asian stroke perspective. Heart Rhythm 2013; 10: $1082-$ 1088.

5. Inoue $\mathrm{H}$. Thromboembolism in patients with nonvalvular atrial fibrillation: Comparison between Asian and Western countries. J Cardiol 2013; 61: $1-7$.

6. Wang KL, Chiang CE. Optimal international normalized ratio for atrial fibrillation in Asians and Japanese: Do we really know? Circ J 2013; 77: 2242-2243.

7. Bang OY, Hong KS, Heo JH, Koo J, Kwon SU, Yu KH, et al. New oral anticoagulants may be particularly useful for Asian stroke patients. J Stroke 2014; 16: 73-80.

8. Camm AJ, Lip GY, De Caterina R, Savelieva I, Atar D, Hohnloser SH, et al. 2012 focused update of the ESC Guidelines for the management of atrial fibrillation: An update of the 2010 ESC Guidelines 
for the management of atrial fibrillation: Developed with the special contribution of the European Heart Rhythm Association. Eur Heart J 2012; 33: 2719-2747.

9. Inoue $\mathrm{H}$, Atarashi $\mathrm{H}$, Okumura K, Yamashita T, Kumagai N, Origasa $\mathrm{H}$; for the J-RHYTHM Registry Investigators. Thromboembolic events in paroxysmal vs. permanent non-valvular atrial fibrillation: Subanalysis of the J-RHYTHM Registry. Circ J 2014; 78: 2388-2393.

10. Okumura $\mathrm{K}$, Inoue $\mathrm{H}$, Atarashi $\mathrm{H}$, Yamashita $\mathrm{T}$, Tomita $\mathrm{H}$, Origasa H; J-RHYTHM Registry Investigators. Validation of CHADS-VASc and HAS-BLED scores in Japanese patients with nonvalvular atrial fibrillation: An analysis of the J-RHYTHM Registry. Circ J 2014; 78: $1593-1599$.

11. Inoue $\mathrm{H}$, Atarashi $\mathrm{H}$, Okumura $\mathrm{K}$, Yamashita $\mathrm{T}$, Origasa $\mathrm{H}$, Kumagai $\mathrm{N}$, et al. Impact of gender on the prognosis of patients with nonvalvular atrial fibrillation. Am J Cardiol 2014; 113: 957-962.
12. JCS Joint Working Group. Guidelines for pharmacotherapy of atrial fibrillation (JCS 2013): Digest version. Circ J 2014; 78: 1997-2021.

13. Ruff CT, Giugliano RP, Braunwald E, Hoffman EB, Deenadayalu $\mathrm{N}$, Ezekowitz MD, et al. Comparison of the efficacy and safety of new oral anticoagulants with warfarin in patients with atrial fibrillation: A meta-analysis of randomised trials. Lancet 2014; 383: $955-$ 962.

14. Friberg L, Rosenqvist M, Lip GY. Evaluation of risk stratification schemes for ischaemic stroke and bleeding in 182678 patients with atrial fibrillation: The Swedish Atrial Fibrillation Cohort study. Eur Heart J 2012; 33: 1500-1510.

15. Olesen JB, Lip GY, Hansen ML, Hansen PR, Tolstrup JS, Lindhardsen $\mathrm{J}$, et al. Validation of risk stratification schemes for predicting stroke and thromboembolism in patients with atrial fibrillation: Nationwide cohort study. BMJ 2011; 342: d124, doi:10.1136/bmj.d124. 